American Journal of Agricultural and Biological Sciences 4 (2): 156-166, 2009

ISSN 1557-4989

(C) 2009 Science Publications

\title{
Effect of Methyl Cellulose Coating and Pre-Treatment on Oil Uptake, Moisture Retention and Physical Properties of Deep-Fat Fried Starchy Dough System
}

\author{
${ }^{1}$ Jihad M. Quasem, ${ }^{2}$ Ayman Suliman Mazahreh, ${ }^{3}$ Khaled Abu-Alruz, ${ }^{4}$ Ibrahim A. Afaneh, \\ ${ }^{5}$ Ala'a H. Al-Muhtaseb and ${ }^{6}$ T.R.A. Magee \\ ${ }^{1}$ Department of Medical Allied Science, Zarka University Collage, Al-Balqa' \\ Applied University, Zarka, Jordan \\ ${ }^{2}$ Department of Applied Science, Al-Balqa Applied University, \\ Princes Alia University College, P.O. Box 941941 Zarqa11194, Jordan \\ ${ }^{3}$ Department of Food Science and Nutrition, Faculty of Allied Medical Sciences, \\ Applied Science University, Amman, Jordan \\ ${ }^{4}$ Department of Food Processing, Faculty of Science and Technology, \\ Al-Quds University, P.O. Box 20002, Jerusalem, Via Israel \\ ${ }^{5}$ Department of Chemical Engineering, Faculty of Mining and Environmental Engineering, \\ Al-Hussein Bin Talal University, Ma'an 20, Jordan \\ ${ }^{6}$ School of Chemistry and Chemical Engineering, Queen's University Belfast, \\ David Keir Building, Stranmillis Road, Belfast BT9 5AG, UK
}

\begin{abstract}
Problem statement: The influence of edible methyl cellulose coating and blanching pretreatment in reducing oil uptake and moisture loss during frying of starchy dough system was investigated. Approach: Potato dough cylinder of $60 \mathrm{~mm}$ length and $22 \mathrm{~mm}$ diameter was used as a model food system. Samples were coated with $0.5 \%$ methyl cellulose film-forming solution and uncoated samples were used as control. Compared to the control samples, a reduction of $80 \%$ in oil uptake was achieved, with an increase in frying temperature decreasing the oil uptake due to the gel formation of methyl cellulose which was enhanced by higher temperatures. Results: No effect of methyl cellulose coating on the final moisture content was observed. The effect of methyl cellulose coating on structural properties (diameter, length, volume and bulk density) was also examined. The results showed that methyl cellulose coating had a significant effect on dimensional and density changes, as it enhanced the formation of crust, leading to a buildup in pressure within the cylinder, which in turn caused considerable puffing of the sample. Conclusion: Blanching pre-treatment $\left(100^{\circ} \mathrm{C}, 5 \mathrm{~min}\right)$ was found to be effective in reducing the oil content of the potato dough samples.
\end{abstract}

Key words: Edible coating, methyl cellulose, blanching, deep-fat frying, starch system, physical properties

\section{INTRODUCTION}

One of the primary objectives of food processing is to increase food palatability. Deep fat frying is a widely used method for preparing foods with an attractive and tasty surface. The soft and moist interior along with the porous crispy crust provides increased palatability to foods ${ }^{[39]}$. Deep-fat fried food constitutes a major part of daily food consumption ${ }^{[26]}$. French fried potatoes represent one of the major items in the food market, either as a processed product or as a frozen par-fried ${ }^{[17]}$. However, during deep fat frying of French fried potatoes, the moisture content decreases from approximately $80-2 \%$. This high removal inevitably leads to a considerable oil uptake which amounts to about $35-45 \%$ of the chip mass; this high consumption of fat is a key dietary contributor to high blood cholesterol, high blood pressure, coronary heart diseases and conducive to obesity ${ }^{[1]}$. Hence, due to consumer health concerns and the trend toward healthier and low-fat food products, intensive research has been undertaken to reduce the amount of fat absorbed in the fried foods. Various factors affect the quality of the fried product, such as temperature of the

Corresponding Author: Jihad M. Quasem, Department of Medical Allied Science, Zarka University Collage,

Al-Balqa' Applied University, Zarka, Jordan 
heated oil, frying duration, frying oil volume, types of oil, product composition, shape, porosity, moisture content and pre-treatment of the food product ${ }^{[35]}$.

Early results obtained by Pravisani and Calvelo ${ }^{[42]}$ showed that oil content was independent on the frying temperature, range between 155 and $200^{\circ} \mathrm{C}$. This result is in agreement with Gamble et al..$^{[13,14]}$ and Moreira et al. ${ }^{[24]}$ who studied the effect of different frying temperatures on potato crisps, tortilla chips, plantain slice and plantain slices, respectively. The former found that although the early stages of frying showed the lower oil temperature resulted in lower oil content, but the overall oil content is temperature independent within the oil temperature examined. However, Lisinska and Leszczynski ${ }^{[41]}$ found out that potato chips fried at higher oil temperature for a short period of time contain less oil than those fried at lower temperatures. Moyano and Pedreschi ${ }^{[26]}$ found out that oil uptake increased approximately by $32 \%$ as the frying temperature decreased from 180 to $120^{\circ} \mathrm{C}$ at moisture content $\leq 1 \mathrm{~g}$ water/g dry solid. They also reported that oil uptake was high even for short frying times at the different temperatures tested $\left(120-180^{\circ} \mathrm{C}\right)$ suggesting that oil wetting is an important mechanism oil uptake during frying. Ufheil and Escher ${ }^{[39]}$ confirmed experimentally, that most of the oil is absorbed when the product is removed from the oil bath and suggested that oil uptake is primarily a surface phenomenon. Moreira et al. ${ }^{[24]}$ also found that most of the oil penetrates within the structure of a tortilla chip during the post-frying cooling period and not during immersion. They found that only $20 \%$ of the oil is absorbed during the immersion period, while $64 \%$ of the total oil content is absorbed during post-frying cooling, suggesting that oil absorption is related to capillary pressure differences. Diaz et al ${ }^{[8]}$ found that during frying, oil uptake have two stages; the first stage remarked as considerable oil content between 0 and $20 \mathrm{sec}$ and the second stage was starting at $20 \mathrm{sec}$, which noted as a decrease in the oil uptake rate. Pedreschi et $a l .{ }^{[27]}$ analyzed oil penetration into potato cylinders during deep-fat frying, distinguishing between the different oil fractions that are absorbed during the process: Structural oil (absorbed during frying), penetrated surface oil (surface oil suctioned during cooling) and surface oil (fraction of oil that remains on the surface). They found that only a small amount of oil is absorbed as 'structural oil' during the immersion period, since the vigorous escape of water vapor precludes oil migration into the porous structure. Thus, they demonstrated that most of the oil was picked up at the end of the process, suggesting that oil uptake and water removal are not synchronous phenomena.
Pedreschi et al. ${ }^{[27]}$ also reported that penetrated surface oil constituted the highest fraction of the total oil content, confirming that oil absorption in potato chips is mainly a surface phenomenon.

Moreira et al. ${ }^{[25]}$ exhibit the effect of frying time on the moisture content of tortilla chip. They elucidated that although the result shows a moisture decrease along the frying period $(60 \mathrm{sec})$; tortilla chips losses most of its moisture content within the first $15 \mathrm{sec}$. This observation was in agreement with the work of Diaz et $a l^{[8]}$ who reported a similar trend when examining the moisture loss in the frying of different types of plantain for different frying time. They found that the drop in moisture content was higher during the first $90 \mathrm{sec}$ frying than with the long frying time.

Many approaches to reduce oil absorption in fried products have been reported in the literature, which are focused on cooking technology (time/temperature), ingredients addition (chemical compounds) and pretreatment (pre-drying, osmotic pre-treatment and blanching ${ }^{[32]}$. Bunger et al ${ }^{[4]}$ reported that potato strips soaked in $3 \% \mathrm{NaCl}$ solution for $50 \mathrm{~min}$ prior to frying significantly reduced oil uptake from $0.13-0.10 \mathrm{~g}$ oil $/ \mathrm{g}$ dry matter. However, soaking had no effect on moisture loss during deep fat frying. Rubnov and Saguy ${ }^{[33]}$ added fructose to restructured potato samples which resulted in a change of the surface properties, with a reduction of absorbed oil. Krokida et al. ${ }^{[20]}$ examined the use of osmotic dehydration as a pre-treatment to produce lowfat French fries, where four types of solutions (sugar, $\mathrm{NaCl}$, maltodextrine 12 and maltodextrine 21) were used. The results showed that osmotic pre-treatment decreases oil and moisture content. Rimac et al. ${ }^{[32]}$ investigated the influence of osmotic pre-treatment, using $0.5 \% \mathrm{NaCl}$ solution, on the oil absorption in fried potato. The results obtained have shown the pre-frying treatment considerably decreased the oil absorption by $28 \%$. Mai Tran et al. ${ }^{[22]}$ reported that crisp samples, soaked in sugar solution (23 wt \%) for $2 \mathrm{sec}$ before frying, had about $30 \%$ less oil than untreated samples. However, treatment did not affect the final moisture content of crisps.

Recently, much attention has been given to the use of hydrocolloids (long chain polymers), especially cellulose derivatives, as potential solutions by forming a barrier to fat absorption during the frying process ${ }^{[34]}$. Hydrocolloids have been used as multifunctional additives in food processing. They are added to control and to improve functional properties like viscosity, water binding capacity and emulsion stability ${ }^{[32]}$. Hydrocolloids are of a special interest because they possess good barrier properties to oxygen, carbon dioxide and lipids ${ }^{[40]}$. Applicable hydrocolloids include 
proteins, cellulose derivatives, alginates, pectins, starches and other polysaccharides ${ }^{[1]}$.

Feeney et $a l^{[12]}$ reported the used corn zein as an edible coating in French fried potatoes and reported a $28 \%$ reduction in oil uptake. Mallikarjunan, Chinnan, Balasubramaniam and Phillips ${ }^{[23]}$ found that a reduction of 59, 61 and $83 \%$ in fat uptake was observed for samples coated with Corn Zein (CZ), HPMC and Methyl Cellulose (MC), respectively. Rimac et al. ${ }^{[32]}$ mentioned that $54 \%$ reduction in oil content was achieved by blanching potato strips in $0.5 \%$ calcium chloride solution followed by immersion in $1 \%$ solution of Carboxymethyl Cellulose (CMC). Salvador et al. ${ }^{[34]}$ reported that methyl cellulose performed effectively in reducing the amount of fat absorbed in a wide variety of battered food items (marrow, meat and squid). Suarez, Campanone, Garcia and Zaritzky ${ }^{[3]}$ studied the effect of edible methyl cellulose coating in reducing oil uptake during frying of a dough system. The oil uptake reduction was $30 \%$ for coated dough samples, with no effect on the final moisture content and the quality, such as color and texture.

On reviewing the available literature, it is evident that extensive research has been carried out to address various aspects of the frying phenomena. However, the use of edible ingredients as a surface treatment and their effect on the oil uptake and water content during frying are relatively limited in the literature. Therefore, gathering more relevant data is necessary to promote knowledge, simplify and delimit the subject to some extent. With this in mind, the aim of this study was to (1) Examine the relationship between moisture loss and oil adsorption with frying temperature and time; (2) Investigate the influence of edible film coating (carboxymethyl cellulose) and osmotic pre-treatment ( $\mathrm{NaCl}$, surface active agent, amylose) on the oil content reduction and water loss phenomena during the frying of starchy food systems.

\section{MATERIALS AND METHODS}

Potato: Potato samples (Pentland Dell variety), were stored in darkness at $4 \pm 0.5^{\circ} \mathrm{C}$ before processing. After stabilizing at room temperature for at least $24 \mathrm{~h}$ prior to use, the potato samples peeled, thoroughly cleaned, washed and then trimmed, samples of the appropriate size were cut using a cylindrical stainless steel die. The samples were taken from the central medulla region of the potato, due to the existence of a more uniform cell structure. The samples were all cored along the longitudinal axis in order to provide one morphological cell structure. The cored sample $(16 \pm 0.5 \mathrm{~mm}$ length and $19 \mathrm{~mm}$ diameter) was then trimmed on a slicer (SL400
Food Slicer, Kenwood, UK) to give smooth and perpendicular edges. Samples were then rinsed in distilled water to eliminate some starch material adhering to the surface. Any surface moisture present was adsorbed with filter paper and then weighed using a top-loading electronic balance (Denver Instrument ${ }^{\circledR}$, Model S-403) with an accuracy of $\pm 0.001 \mathrm{~g}$.

Osmotic pre-treatment: Potato samples were immersed in sodium chloride (AnalaR, BDH Laboratory Supplies, UK) solutions of 5, 10 and $15 \%(\mathrm{w} / \mathrm{w})$ concentration for 1,4 and $8 \mathrm{~h}$. Following the osmosis period, the samples were removed, rinsed and then blotted with filter paper to remove surface moisture.

Soaking in amylose solution: Potato samples were soaked for $30 \mathrm{~min}$ in a $1.5 \%(\mathrm{w} / \mathrm{w})$ solution of amylose (Corn Amylose, Practical Grade, Sigma, USA). Following the soaking period, the samples were removed, rinsed and then blotted with filter paper to remove surface moisture.

Dipping in surfactant: Potato samples were immersed in polyoxyethylene-sorbitan-monolaurate (Tween 20) (BDH Laboratory Supplies, UK) solutions of $0.1,0.5$ and $1 \%(\mathrm{w} / \mathrm{w})$ concentration for $5 \mathrm{~min}$. Following the soaking period, the samples were removed, rinsed and blotted with filter paper to remove surface moisture.

Dipping in Carboxyl Methyl Cellulose (CMC) solution: Two investigations were carried out: (i) samples were immersed in a $0.05 \%(\mathrm{w} / \mathrm{w})$ solution of CMC (Aqualon Division, Hercules Ltd, UK.) for $5 \mathrm{~min}$. Following soaking, the samples were removed and then blotted with filter paper to remove surface moisture; (ii) samples were dried to $15 \%$ (wet basis) in a convective oven at $70 \pm 0.05^{\circ} \mathrm{C}$, cooled and immersed in a $0.05 \%$ (w/w) CMC solution for $5 \mathrm{~min}$. Following soaking, the samples were removed and then blotted with filter paper to remove surface moisture.

Experimental procedure: The frying experiments were performed in a commercial deep fat fryer (Kenwood) with temperature controller of $\pm 1^{\circ} \mathrm{C}$. The oil temperature was also monitored using a type $\mathrm{K}$ thermocouple (Omega Engineering). The fryer was filled with 21 of sunflower oil and set to one of the required operating temperatures $(135,150,165$ and $180^{\circ} \mathrm{C}$ ). The oil was preheated for approximately one 1 $\mathrm{h}$ prior to frying to ensure steady-state conditions. A pre-weighed, single cylindrical sample was then positioned on a metal mesh basket, immersed in the hot oil and fried for a predetermined period of time $(0.5$, 
$1.5,3,4.5,6,7.5,9$ and $10.5 \mathrm{~min}$ ) to determine the amount of oil uptake and water loss in the samples as function of time. Fried samples were removed from the unit and the excess surface oil absorbed with filter paper. Samples were then allowed to cool to room temperature for $5 \mathrm{~min}$ before moisture and oil content analysis was done, using the methods detailed in the following sections. After each frying test, oil level was checked and replenished; oil was changed after $1 \mathrm{~h}$ of frying time. The frying characteristics of the cylindrical potato samples were investigated with regard to the operating parameters of oil temperature, frying time, edible film coating and osmotic pre-treatments. Each experimental run was performed in triplicate.

Oil content determination: The oil content of the sample was determined using soxhlet extraction according to the method Aa 4-38 of the AOCS (1993). Samples were dried to constant weight in a vacuum oven at $70^{\circ} \mathrm{C}$ prior to extraction. The dried samples then grounded in a blender and extracted with $250 \mathrm{~mL}$ petroleum ether for $4 \mathrm{~h}$. Petroleum ether was recovered under vacuum at $60^{\circ} \mathrm{C}$ by a rotary evaporator. The recovered oil was left for $24 \mathrm{~h}$ in a vacuum oven at $70^{\circ} \mathrm{C}$ and weighted.

Moisture content determination: The moisture content of the sample, raw or fried, was determined gravimetrically by drying representative triplicate samples in a conventional oven at $105^{\circ} \mathrm{C}$ for $8-10 \mathrm{~h}^{[2]}$.

\section{RESULTS}

Influence of methyl cellulose emulsifying agent: Preliminary experiments were conducted using potato dough cylinders without emulsifying agent (MC). However, the sample was found to disintegrate after frying for approximately $180 \mathrm{sec}$ (at $150^{\circ} \mathrm{C}$ or higher). Therefore, subsequent experiments were carried out using potato dough cylinders fortified with methyl cellulose emulsifier $(0.5 \% \mathrm{w} / \mathrm{w})$; the emulsifier acted as a binder. In a preliminary study the frying characteristics of potato dough (without emulsifier), potato dough (with emulsifier) and potato at $165^{\circ} \mathrm{C}$ were compared. Comparison of the moisture and oil contents of the samples, as shown in Fig. 1 and 2, reveal an added advantage of emulsifier addition to the dough.

A more in-depth series of frying experiments were then undertaken using potato dough (with emulsifier) as the raw material. As shown in Fig. 3, the experimental results for the potato dough exhibited the expected trend with respect to moisture content, i.e., the moisture loss was found to increase with increasing frying time and temperature. The experimental moisture content data were most accurately fitted to an exponential function with respect to time. In contrast, a linear relationship was reported by Gamble et al. ${ }^{[13,14]}$ and Reddy and Dias ${ }^{[31]}$.

The effect of frying temperature on moisture content is in agreement with numerous researchers including ${ }^{[6,7,18,19,22-24,30]}$.

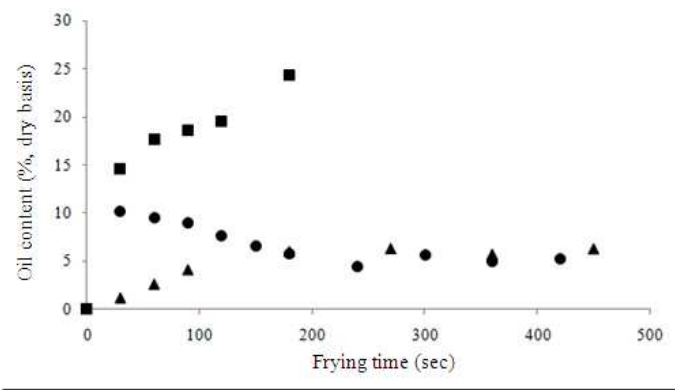

A Potato Potato dough without emulsifying agent $\bullet$ Potato dough with emulsifying agent

Fig. 1: Effect of emulsifier (MC) on the oil uptake during frying at $165^{\circ} \mathrm{C}$ (cylinder- $60 \mathrm{~mm}$ length, $22 \mathrm{~mm}$ diameter)

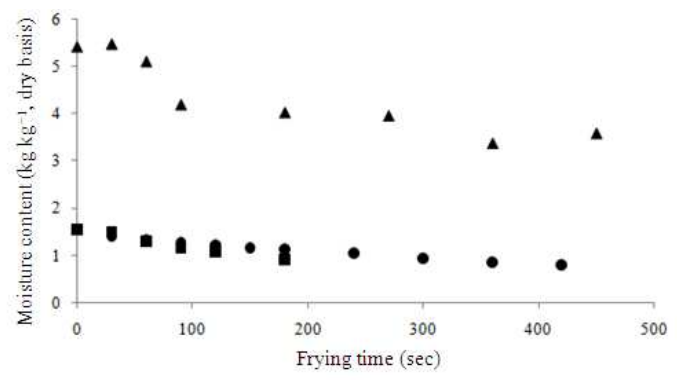

A Potato - Potato dough without emulsifying agent $\bullet$ Potato dough with emulsifying agent

Fig. 2: Effect of emulsifier (MC) on moisture content during frying at $165^{\circ} \mathrm{C}$ (cylinder- $60 \mathrm{~mm}$ length, $22 \mathrm{~mm}$ diameter)

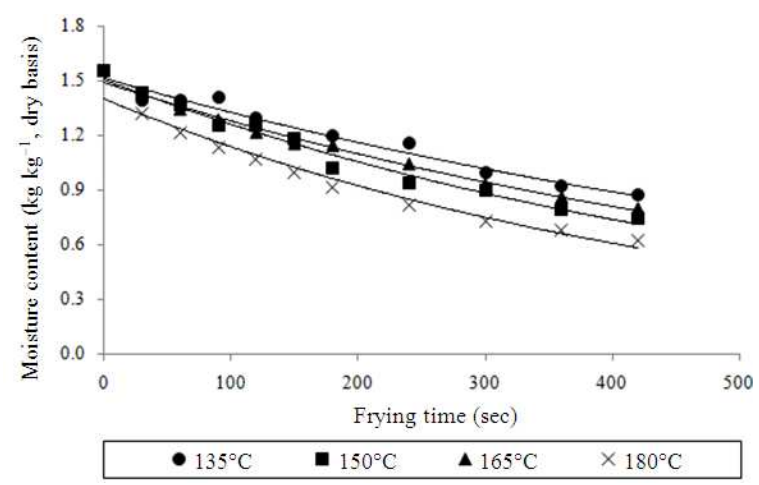

Fig. 3: Variation in moisture content with frying time and temperature (potato dough cylinder-60 mm length, $22 \mathrm{~mm}$ diameter) 
Am. J. Agri. \& Biol. Sci., 4 (2): 156-166, 2009

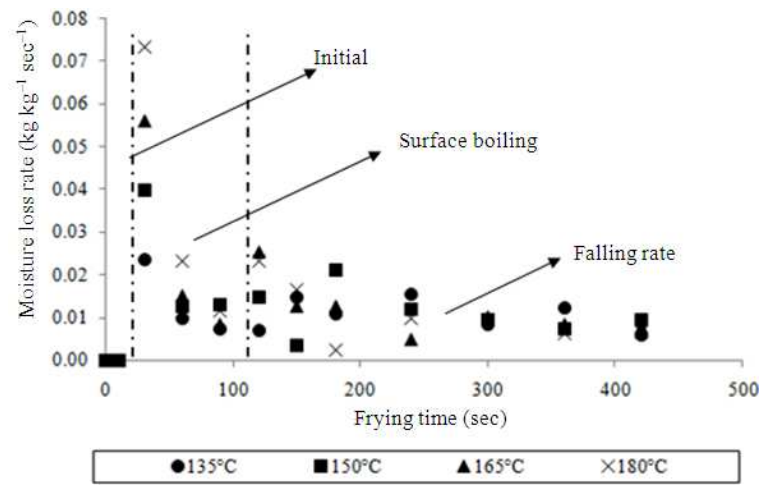

Fig. 4: Variation in moisture loss rate with frying time and temperature (potato dough cylinder- $60 \mathrm{~mm}$ length, $22 \mathrm{~mm}$ diameter)

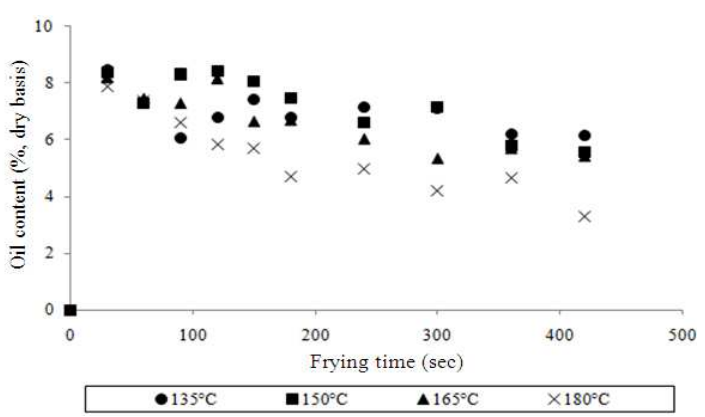

Fig. 5: Variation in oil content with frying time and temperature (potato dough cylinder-60 $\mathrm{mm}$ length, $22 \mathrm{~mm}$ diameter)

The moisture loss data was further represented in terms of the moisture loss rate, as shown in Fig. 4. Three stages of moisture loss could be identified in the moisture loss rate versus time graph.

The corresponding oil content results for the potato dough (with emulsifier) samples are shown in Fig. 5. The maximum oil content was observed within the first $60 \mathrm{sec}$, followed by a continual decrease as the frying progressed.

Influence of blanching: Blanching is a pre-treatment method adopted during vegetable frying processes to enhance the frying characteristics and hence, product quality $^{[15]}$.

Figure 6 shows that the oil content of the pre-fry blanched sample has less oil compared to the standard sample (no pre-fry treatment).

As shown in Fig. 7, blanching also has a slight effect on the final moisture content of the samples. This is in agreement with the results of ${ }^{[18]}$, who stated that blanching has an effect on the rates of moisture reduction of potato chips samples, due to starch gelatinization.

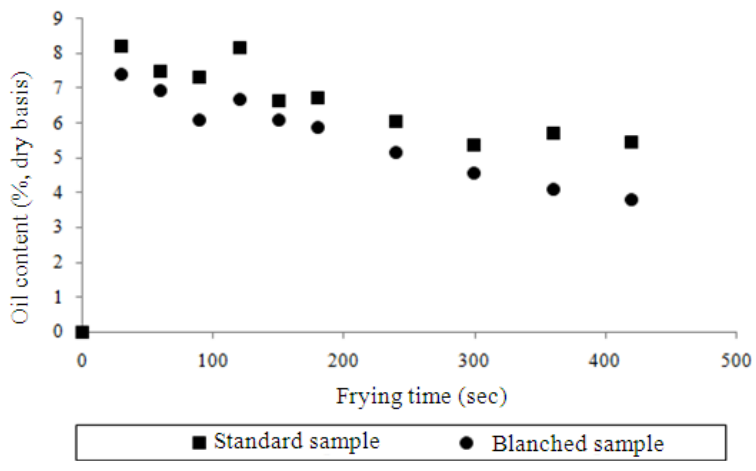

Fig. 6: Effect of blanching treatment on sample oil content during frying at $165^{\circ} \mathrm{C}$ (potato dough cylinder-60 mm length, $22 \mathrm{~mm}$ diameter)

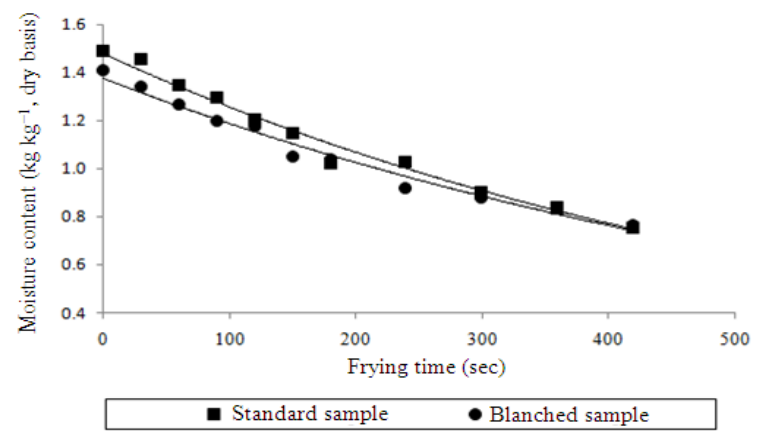

Fig. 7: Effect of blanching treatment on sample moisture content during frying at $165^{\circ} \mathrm{C}$ (potato dough cylinder- $60 \mathrm{~mm}$ length, $22 \mathrm{~mm}$ diameter)

Debnath et $a l .{ }^{[7]}$ found that pre-fry drying had a significant effect on the moisture kinetic coefficient during deep fat frying of chickpea flour-based snack food.

Potato dough with varying initial moisture content: In order to simulate products with differing initial moisture content, but the same structural characteristics, potato dough samples with initial contents of 1.0, 1.5 and $2.0 \mathrm{~kg} \mathrm{~kg}^{-1}$ (dry basis) were prepared and fried at $165^{\circ} \mathrm{C}$. The oil uptake and the moisture loss rate were expected to be higher for the sample of higher initial moisture content. The experimental oil content data are shown in Fig. 8.

\section{Physical properties:}

Dimensional changes: Potato dough samples were fried at $135,150,165$ and $180^{\circ} \mathrm{C}$ for different frying times and the dimensional changes (diameter and length) monitored. The diameter decreased as the water exited the potato dough. The cylinder was then pushed gently outwards by internal pressure. The results are shown in Fig. 11 and 12, respectively. 


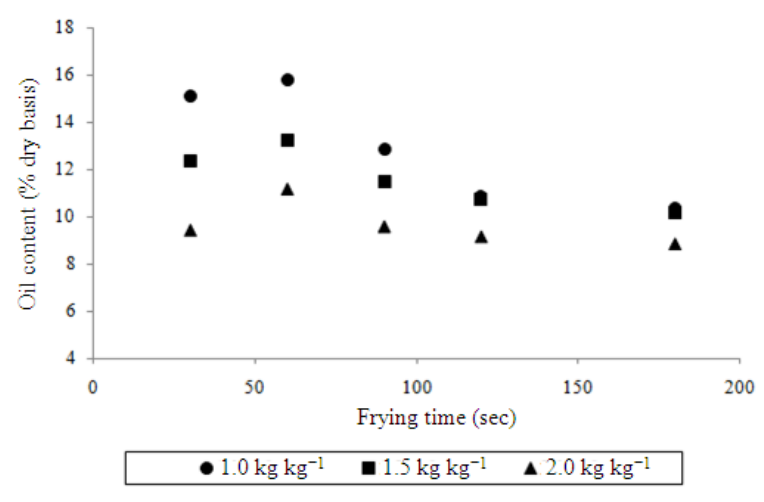

Fig. 8: Effect of initial moisture content on sample oil content during frying at $165^{\circ} \mathrm{C}$ (potato dough cylinder- $60 \mathrm{~mm}$ length, $22 \mathrm{~mm}$ diameter)

Density: The variation in the density of potato dough samples during frying at different temperatures was also examined, as shown in Fig. 13, where it can be observed that it falls significantly during frying. Frying temperature was also found to affect the density, which decreases with increasing temperature, at a given time.

\section{DISCUSSION}

As shown in Fig. 1, the presence of emulsifier resulted in a significant decrease in the oil content of the sample. This may be attributed to the fact that following gelatinization, which takes place after approximately $30 \mathrm{sec}$, the emulsifier acts as oil barrier. The insoluble, oil gel formed causes the oil to diffuse in a counter direction (from the inside to the outside of the food). Although the emulsifier accelerated the formation of the crust, as revealed visually, this crust offers a barrier for oil penetration in comparison to the crust formed on sample without emulsifier (this has properties favorable to oil uptake). The final oil content of the dough (with emulsifier) was found to be comparable to that of the potato sample. This is in agreement with ${ }^{[3,8,13,17,23,28,32,34]}$, who also reported the barrier effect which a crust has on oil uptake.

As shown in Fig. 2, the presence of emulsifier had a negative effect on the moisture loss from the dough sample. No effect on the final moisture content was observed. On comparison of potato and potato dough moisture loss curves, it can be seen that the relative degree of moisture loss is much lower for the potato dough. This could be attributed to the sample structure, with the dough samples having a decreased number of pores through which moisture can escape, compared with potato and also due to the properties of the coating film. Methyl cellulose coating film acted as protective layer reducing material loss from the surface ${ }^{[23]}$.
During the early stage of frying, there is an initial heating period when no water is lost. Heat is transferred from the oil to the food via convection at the surface and conduction through the uncooked solid and the temperature of the food approaches the temperature of vaporization of the liquid present, i.e., the food temperature approaches $100^{\circ} \mathrm{C}^{[11]}$. This initial, shortheating phase was observed to proceed for approximately $10 \mathrm{sec}$. During this period all the heat entering the potato was used for sensible heating, with only a small amount of expanded air leaving the potato. Such observations are in accordance with those of Farkas ${ }^{[11,37]}$ who reported that during the first stage of frying no evaporation of moisture occurred and the heat was transferred in convection mode between the oil and the sample. This period was followed by a sudden loss of moisture, characterized by formation of a larger number of small bubbles, which form over the entire surface of the sample and leave rapidly. The maximum water loss rate, in the period of 'surface boiling' occurs at between 30 and $100 \mathrm{sec}$. This surface boiling increases the heat transfer coefficient, which in turn allows more heat to be transferred to the food for the vaporization of water ${ }^{[24]}$. The rate of moisture loss was then observed to fall as the sample crust thickened; the moisture driving force and moisture content decreases. The formation of water vapor bubbles becomes limited to a relatively small number of formation sites. It is probable that these sites represent weak or damaged areas of the potato dough. It is worthy of note that qualitative evaluation of the operating oil temperature could be carried out by observing the volume of bubbles being formed during the early stages of frying.

The water loss rate decreases gradually until the bubble end point is reached and the potato dough was at its equilibrium moisture content (after approximately $120 \mathrm{sec}$ of frying time at $165^{\circ} \mathrm{C}$ ). This is in agreement with $^{[7,20,22]}$ who reported that the initial moisture loss was rapid and this was followed by a constant rate drying period.

During the first $60 \mathrm{sec}$ of frying the oil replaces the lost moisture, however, as the frying progresses the methylcellulose begins to gelatinize forming a barrier (protective layer) on the cylinder surface, thus restricting further oil uptake. The dependence of oil uptake on temperature is opposite to that observed during the frying of potato, with an increase in frying temperature decreasing the oil uptake.

For low frying temperatures (below $135^{\circ} \mathrm{C}$ ), although the oil temperature is sufficient to enhance the effect of methyl cellulose (gel formation), a certain amount of oil is still allowed to diffuse into the 
cylinder. However, at high frying temperatures $\left(150^{\circ} \mathrm{C}\right.$ and above) gel formation of methyl cellulose will be enhanced, resulting in less oil entering the sample. From frying temperatures greater than $150^{\circ} \mathrm{C}$, the barrier formed causes a buildup of internal pressure, leading to the sample 'exploding' after a period of approximately $420 \mathrm{sec}$. Lower oil content during frying at a higher temperatures is in accordance with the results of ${ }^{[25-27,30]}$.

This is due to the blanching effect on potato dough structure. Gelatinization of the potato dough prior to frying enhanced the resistance to oil uptake. This may be due to gel formation decreasing the pores on the cylinder surface. Selman and Hopkins ${ }^{[36]}$, Lamberg et al. ${ }^{[21]}$, Debnath et al. ${ }^{[7]}$, Rimac et al. ${ }^{[32]}$ and Pedreschi and Moyano $^{[26]}$ also found that pre-drying increases the crispness dramatically and significantly reduces the oil absorption of the blanched potato slices after frying.

The oil content at a given time was higher for samples with lower initial moisture content. This is due to crust formation and its favorable oil uptake characteristics. The $1.0 \mathrm{~kg} \mathrm{~kg}^{-1}$ sample has the lowest moisture content, thus crust formation was faster and therefore, oil uptake was higher. Therefore, it would appear that the effect of crust, which was enhanced by the addition of methylcellulose, had the greater effect than sample moisture content on the oil uptake characteristics. The corresponding moisture loss data and equations are shown in Fig. 9 and Table 1. Given that the moisture content plots display similar trends as confirmed by ' $b$ ' values of equal magnitude (Table 1), this indicates that the moisture loss rate is not affected significantly by initial moisture content.

At a given frying time, the final moisture content is dependent on the initial moisture content and frying conditions. Therefore, to eliminate the effect of the initial moisture content, it is more appropriate to compare the experimental data by adopting the parameter, oil content criterion $\left(U_{R}\right)$. This parameter is defined as the amount of oil uptake (g) divided by the amount of water lost (g). The experimental data were recalculated on this basis and the results are shown in Fig. 10.

The initial moisture content of the potato dough significantly affected the oil content criterion. The lower initial moisture content resulted in a higher oil uptake to water loss ratio. The higher initial moisture content results in pores of smaller radius being formed during frying due to the higher water diffusion rate ${ }^{[24]}$. Materials with a lower initial moisture content usually have higher porosity and have a greater tendency to build up pressure within the pores during frying, thus causing an enlargement of the pore size which results in a lower pressure drop for oil absorption, particularly during cooling ${ }^{[24]}$.
Table 1: Moisture loss equation and $\mathrm{R}^{2}$ for data plotted in Fig. 9

\begin{tabular}{lll}
\hline Initial moisture content $\left(\mathrm{kg} \mathrm{kg}^{-1}\right.$, dry basis $)$ & Equation* & $\mathrm{R}^{2}$ \\
\hline 1.0 & $\mathrm{y}=0.937 \mathrm{e}-0.002 \mathrm{t}$ & 0.934 \\
1.5 & $\mathrm{y}=1.42 \mathrm{e}-0.002 \mathrm{t}$ & 0.934 \\
2.0 & $\mathrm{y}=1.92 \mathrm{e}-0.002 \mathrm{t}$ & 0.968 \\
\hline
\end{tabular}

*: Equation: $\mathrm{y}: \pm \mathrm{a} \times \exp (-\mathrm{bt})$ where, $\mathrm{y}:$ Sample moisture content ( $\mathrm{kg} \mathrm{kg}^{-1}$, dry basis); t: Frying time (sec)

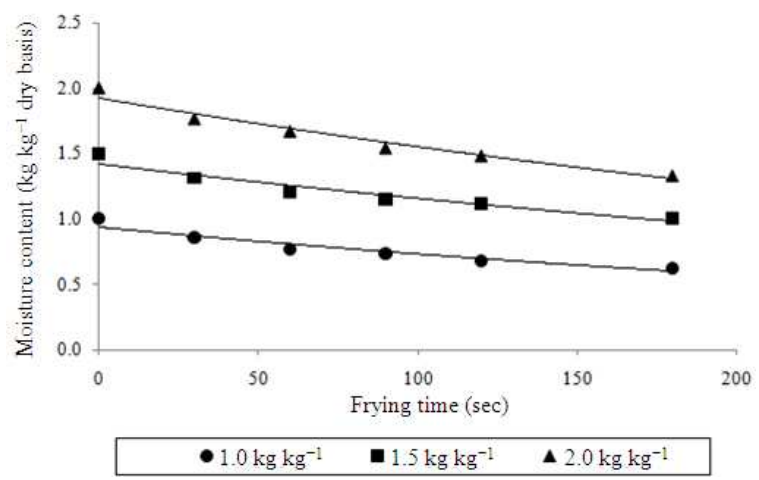

Fig. 9: Effect of initial moisture content on sample moisture content during frying at $165^{\circ} \mathrm{C}$ (potato dough cylinder-60 $\mathrm{mm}$ length, $22 \mathrm{~mm}$ diameter)

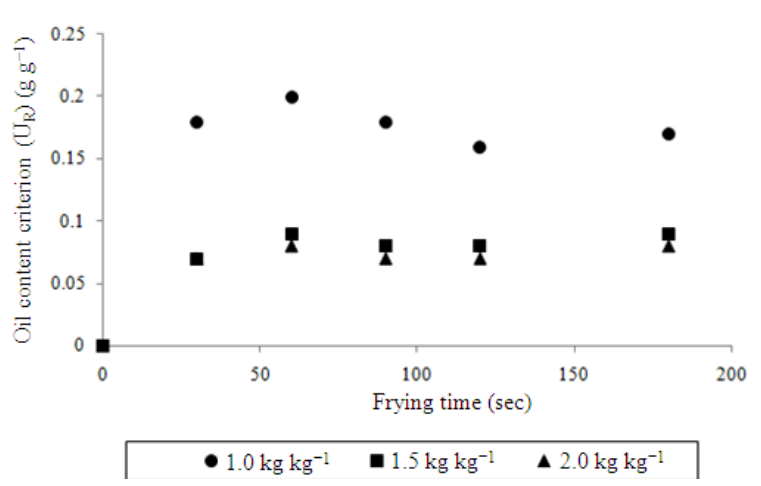

Fig. 10: Oil content criterion against frying time during frying at $165^{\circ} \mathrm{C}$ (potato dough cylinder- $60 \mathrm{~mm}$ length, $22 \mathrm{~mm}$ diameter)

Visual observations were carried out on each sample after frying, by cutting through sample crosssection to observe the internal structure. The crust area (very rigid texture) was clearly distinguished from the inner core of the sample which was completely gelatinized and rubbery in texture. This observation was used to explain the similarities in the moisture loss trend during frying at different moisture content and also different frying temperatures, due to the effect of methyl cellulose. The moisture loss was evenly distributed over the cylinder (visual evidenced for the bubbles) and the oil was forced to locate just within the crust, since the gelatinized internal structure as a barrier 
for oil penetration, along with the resistance caused by the space between the crust and the gelatinized layers. However, the higher initial moisture content delayed the formation of the crust layer. Mallikarjunan et al. ${ }^{[23]}$ stated that moisture removal and consequent fat uptake occur mainly in the crust and, therefore, the role of the edible film coatings in retaining moisture and reducing fat uptake was limited only to the surface.

This is in agreement with ${ }^{[10,21,23,27]}$ who reported that crust is the domain of interest regarding oil penetration since oil deposition during the frying process is mostly limited to the crust region.

As shown, the diameter of the potato dough sample was found to decrease at the onset of frying, irrespective of the frying temperature, due to the moisture evaporation. It was expected that the diameter would continue to decrease as the frying progressed, however, the diameter was found, in fact, to increase. This may be attributed to the presence of methyl cellulose, which gelatinizes during frying to form a solid structure. Although the potato dough losses a significant portion of its water content, the solid matrix remains fixed and it is this structure that ensures that dimensional changes are small. Methylcellulose has the further function of enhancing the formation of crust which leads to a buildup in pressure within the cylinder which in turn causes considerable puffing of the sample. This is revealed through the excluded samples when they had irregular puffing in certain places over the cylinder surfaces or in certain cases of sample explosion. Figure 11 also shows that the effect of time on the diameter changes was more significant than the effect of temperature; however, the effect of temperature was significant on sample length (Fig. 12).

The increase in length is attributed to the proportionately large degree of water movement within the sample in the axial direction toward the cylinder ends (visual evidence for moisture evaporation) which caused them to swell. Therefore, the increase in cylinder length is due to swelling at each end. As shown in Fig. 12, sample length decreased during the first $30 \mathrm{sec}$ of frying, irrespective of frying temperature $\left(135^{\circ} \mathrm{C}\right.$ continued to decrease during the first $\left.120 \mathrm{sec}\right)$. As previously mentioned, the rate of moisture loss per unit area is greater in axial ends than the radial direction. The water movement within the sample towards the two ends created a certain pressure on the internal side of the two plat ends which changed the flat end to a significant concave shape. Therefore, the sample length increased. The increase in length may be partially attributed to crust development. In some cases, surface cracking occurred which led to no internal buildup and hence no visible puffing effect (e.g., $150^{\circ} \mathrm{C}$ diameter result).

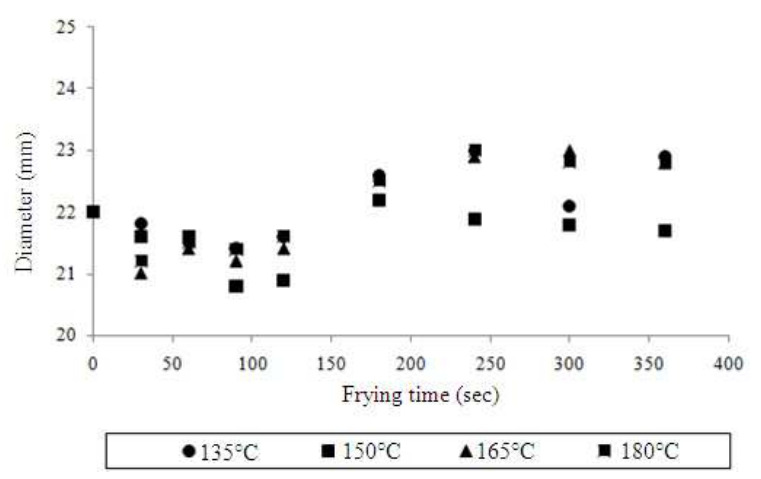

Fig. 11: Variation in sample diameter during frying (potato dough cylinder-60 $\mathrm{mm}$ length, $22 \mathrm{~mm}$ diameter)

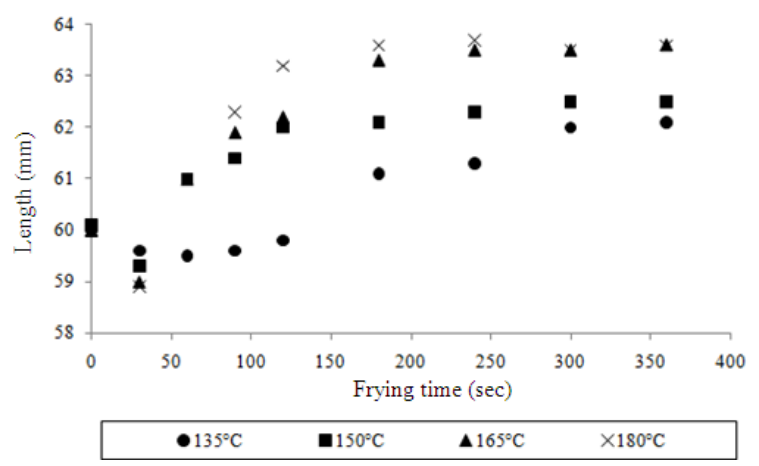

Fig. 12: Variation in sample length during frying (potato dough cylinder-60 mm length, $22 \mathrm{~mm}$ diameter)

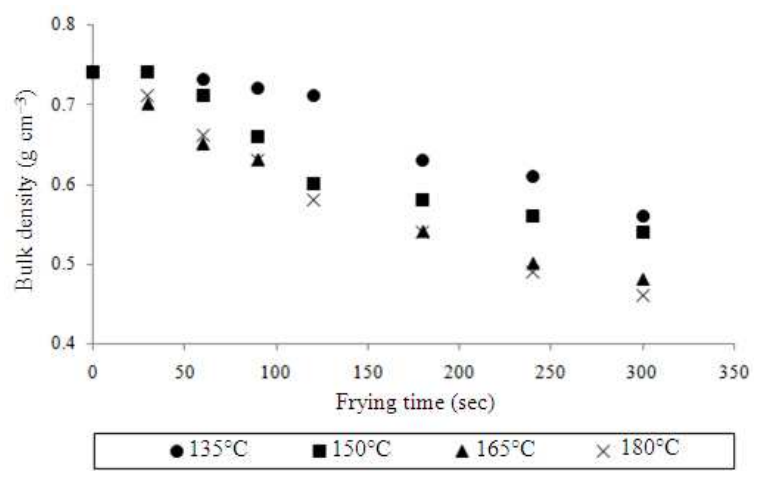

Fig. 13: Variation in bulk density during frying (potato dough cylinder-60 $\mathrm{mm}$ length, $22 \mathrm{~mm}$ diameter) 


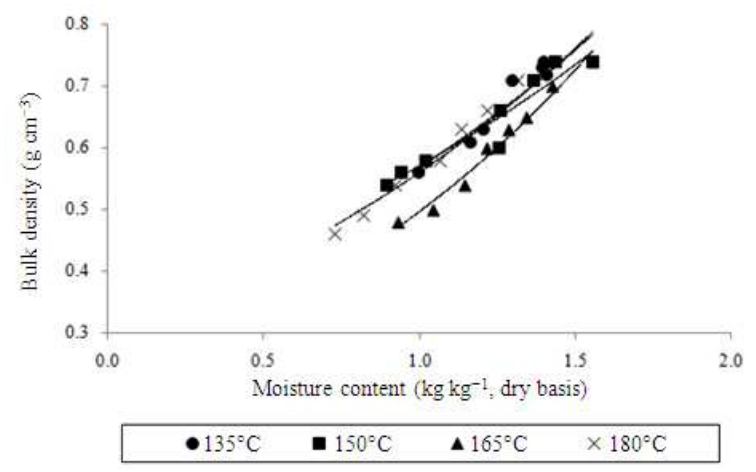

Fig. 14: Variation in bulk density during frying of potato dough with different initial moisture content (cylinder-60 mm length, $22 \mathrm{~mm}$ diameter)

Table 2: Equation and $\mathrm{R}^{2}$ for data plotted in Fig. 14

\begin{tabular}{lll}
\hline Frying temperature $\left({ }^{\circ} \mathrm{C}\right)$ & Equation* & $\mathrm{R}^{2}$ \\
\hline 135 & $\mathrm{y}=0.320 \mathrm{e}-0.576 \mathrm{x}$ & 0.890 \\
150 & $\mathrm{y}=0.343 \mathrm{e}-0.518 \mathrm{x}$ & 0.974 \\
165 & $\mathrm{y}=0.238 \mathrm{e}-0.745 \mathrm{x}$ & 0.976 \\
180 & $\mathrm{y}=0.303 \mathrm{e}-0.613 \mathrm{x}$ & 0.958 \\
\hline
\end{tabular}

*Equation: y: $\pm \mathrm{a} \times \exp (-\mathrm{bx})$, where, y: Bulk density $\left(\mathrm{g} \mathrm{cm}^{-3}\right)$, $\mathrm{x}$ : Sample moisture content $\left(\mathrm{kg} \mathrm{kg}^{-1}\right.$, dry basis)

The results are in contrast to those of ${ }^{[9,29]}$ who reported no changes in restructured potato sample volume during frying. However, Krokida et al. ${ }^{[20]}$ reported that as the drying time increases, the specific volume of French fries samples decreases, which means that the shrinkage phenomenon gets more intense. Kawas and Moreira ${ }^{[16]}$ and Taiwo and Baik ${ }^{[38]}$ reported an increase in the diameter, thickness and volume with time during the frying of tortilla chips and sweet potatoes, respectively.

The relationship between moisture content and density was also determined; as moisture content increased the bulk density increased exponentially, as revealed in Fig. 14 and Table 2. However, it has been mentioned that, while there were slight changes in the dimensions of the potato dough cylinder during frying, the mass of the cylinder decreases considerably. Therefore, the changes in density can be considered to be controlled by the amount of moisture loss rather than dimensional variations. This finding is in agreement with Krokida et al. ${ }^{[20]}$, Kawas and Moreira $^{[16]}$ and Taiwo and Baik $^{[38]}$ who reported a decrease in bulk density as moisture content decreased during frying of French fries, potato, tortilla chips and sweet potatoes, respectively.

Figure 15 shows the variation in volume during the frying process. During the first $30 \mathrm{sec}$ the volume decreased slightly due to the evaporation of water,

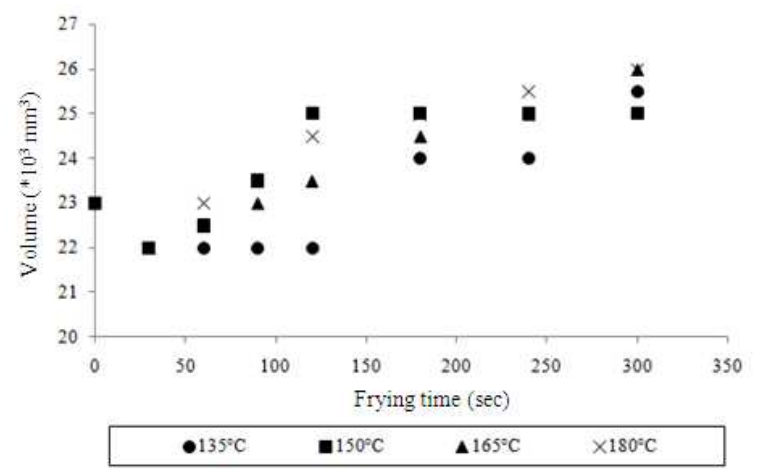

Fig. 15: Variation in sample volume during frying (potato dough cylinder-60mm length, $22 \mathrm{~mm}$ diameter)

irrespective of the frying temperature and the absence of a crust. After $90 \mathrm{sec}$ frying (for a temperature of $165^{\circ} \mathrm{C}$ ) the crusts start forming (the equivalent at $135^{\circ} \mathrm{C}$ is $180 \mathrm{sec}$ ) and thus an internal gradient pressure was formed, hence, the volume exhibits an increase.

\section{CONCLUSION}

The following conclusions can be stated from the present research in which frying of coated starchy food systems has been studied:

- Methyl cellulose emulsifier has been shown to be capable of significantly reducing the amount of oil uptake during frying of potato dough with a negative effect on the moisture loss from the dough sample

- The dependence of oil uptake on temperature is opposite to expectations, with an increase in frying temperature decreasing the oil uptake. Increasing temperature increased the gel formation of methyl cellulose, resulting in less oil entering the sample

- Blanching pre-treatment process affected significantly oil uptake process. Gelatinization of the potato dough sample, prior to frying, decreased the pores on the surface and hence, enhanced the resistance to oil pick up

- The oil content at a given time was higher for samples with lower initial moisture content. This is due, to crust formation and its favorable oil uptake characteristics

- The effect of crust, which was enhanced by the addition of methylcellulose, had the greater effect than sample moisture content on the oil uptake characteristics

- The structural properties were also affected by methyl cellulose coating, which increased the 
diameter and the length of the sample, while the density decreased with time and temperature

\section{ACKNOWLEDGMENT}

Researchers would like to thank Mr., Atalah AlKhalayfeh, at the Department of Chemistry, for his technical support.

\section{REFERENCES}

1. Albert, S. and G.S. Mittal, 2002. Comparative evaluation of edible coatings to reduce fat uptake in a deep-fried cereal product. Food Res. Int., 35: 445-458. http://linkinghub.elsevier.com/retrieve/pii/S096399 6901001399

2. horwitz, 1980. Official Methods of Analysis. AOAC Inc., Washington DC., ISBN: 10: 0935584145, pp: 1038.

3. Bertolini-Suarez, R., L.A. Campanone, M.A. Garcia and N.E. Zaritzky, 2008. Comparison of the deep frying process on coated and uncoated dough systems. J. Food Eng., 84: 383-393.

http://cat.inist.fr/?aModele $=$ afficheN\&cpsidt $=1910$ 2112

4. Bunger, A., P. Moyano and V. Rioseco, 2003. $\mathrm{NaCl}$ soaking treatment for improving the quality of French-fried potatoes. Food Res. Int., 36: 161-166. http://researchspace.auckland.ac.nz/bitstream/2292/ 2318/4/02whole.pdf

6. Chen, Y. and R.G. Moreira, 1997. Modeling of a batch deep-fat frying process for tortilla chips. Food Bioprod. Process., 75: 181-190. http://www.nestle.cl/Revista\%20NSB-10/p31.htm

7. Debnath, S., K.K. Bhat and N.K. Rastogi, 2003. Effect of pre-drying on kinetics of moisture loss and oil uptake during deep fat frying of chickpea flour-based snack food. Lebensm. Wiss. U. Technol., 36: 91-98. http://www.stablemicrosystems.com/papers.htm

8. Diaz, A., G. Trystram, O. Vitrac, D. Dominique and A. Raoult-Wack, 1999. Kinetics of moisture loss and fat absorption during frying for different varieties of plantain. J. Food Sci., 79: 291-299. http://publications.cirad.fr/ur.php?nom=UMR+QU ALISUD

9. Du Pont, M.S., A.R. Kirby and A.C. Smith, 1992. Instrumental and sensory tests of texture of cooked frozen French fries. Int. J. Food Sci. Technol., 27: 285-295.

http://www.springerlink.com/content/q1n1726850g $\mathrm{n} 8 \mathrm{x} 44 /$
10. Farkas, B.E., R.P. Singh and M.J. McCarthy, 1991. Movement of oil/water interface in foods during frying. Proceeding of the Annual Meeting of Institute of Food Technologists, (AMIFT'91), Dallas, TX., pp: 285-295.

11. Farkas, B.E. Singh R. P. and T. R. Rumsey, 1996 Modeling heat and mass transfer in immersion frying. II, model solution and verification. J. Food Eng., 29: 227-248. DOI: 10.1016/02608774(95)00048-8

12. Feeney, R.D., S.G. Haralampu and A.T. Goss, 1993. Potato and other food products coated with edible oil barrier films. US Patent, 5: 217-273. http://www.freepatentsonline.com/5217736.html

13. Gamble, M.H., P. Rice and J.D. Selman, 1987a. Relationship between oil uptake and moisture loss during frying of potato slices from $\mathrm{CV}$ record UK. tubers. Int. J. Food Sci. Technol., 22: 233-241. DOI: /abs/10.1094/CCHEM.2002.79.5.745

14. Gamble, M.H., P. Rice and J.D. Selman, 1987b. Distribution and morphology of oil deposits in some deep fried products. J. Food Sci., 52: 1742-1746. DOI: $10.1111 / \mathrm{j} .1365-2621.1987 . t b 05922 . x$

15. Jayaraman, K.S. and D.K. Das Gupta, 1995. Drying of Fruits and Vegetables. In: Handbook of Industrial Drying, Mujumdar, A.S. (Ed.). Marcel Dekker Inc., New York, pp: 643-690.

16. Kawas, M.L. and R.G. Moreira, 2001. Characterization of product quality attributes of tortilla chips during the frying process. J. Food Eng., 47: 97-107. http://cat.inist.fr/?aModele $=$ afficheN\&cpsidt $=857235$

17. Khalil, A.H., 1999. Quality of French fried potatoes as influenced by coating with hydrocolloids. Food Chem., 66: 201-208. http://cat.inist.fr/?aModele=afficheN\&cpsidt $=1941810$

18. Kingcam, R., S. Devahastin and N. Chiewchan, 2008. Effect of starch retrogradation on texture of potato chips produced by low-pressure superheated steam drying. J. Food Eng., 89: 72-79. http://cat.inist.fr/?aModele=afficheN\&cpsidt=20435409

19. Krokida, M.K., V. Oreopoulou and Z.B. Maroulis, 2000. Water loss and oil uptake as a function of frying time. J. Food Eng., 44: 39-46. http://cat.inist.fr/?aModele=afficheN\&cpsidt $=1291857$

20. Krokida, M.K., V. Oreopoulou, Z.B. Maroulis and D. Marinos-Kouris, 2001. Effect of pre-drying on quality of French fries. J. Food Eng., 49: 347-354. DOI: 10.1016/S0260-8774(00)00233-8

21. Lamberg, I., B. Hallstrom and H. Olsson, 1990. Fat uptake in a potato drying/frying process. Lebensm. Wiss. Technol., 23: 295-300. http://www.actahort.org/members/showpdf?booknr arnr=619_56 
22. Mai Tran, T.T., X.D. Chen and C. Southern, 2007. Reducing oil content of fried potato crisps considerably using a sweet pre-treatment technique. J. Food Eng., 80: 719-726. DOI: 10.1016/j.jfoodeng.2006.06.031

23. Mallikarjunan, P., M.S. Chinnan, V.M. Balasubramaniam and R.D. Phillips, 1997. Edible coatings for deep-fat frying of starchy products. Lebensm. Wiss. U. Technol., 30: 709-714. DOI: 10.1111/j.1745-4549.1998.tb00811.x

24. Moreira, R.G., X. Sun and Y. Chen, 1997. Factors affecting oil uptake in tortilla chips in deep-fat frying. J. Food Eng., 31: 499-510. http://cat.inist.fr/?aModele $=$ afficheN\&cpsidt $=2657148$

25. Moreira, R., J. Palau and X. Sun, 1995. Simultaneous heat and mass transfer during the deep-fat frying of tortilla chips. J. Food Proc. Eng. 18: 307-320.

http://cat.inist.fr/?aModele=afficheN\&cpsidt=3667989

26. Moyano, P. and F. Pedreschi, 2006. Kinetics of oil uptake during frying of potato slices: Effect of pretreatments. Lebensm. Wiss. U. Technol., 39: 285-291. http://www.thapra.lib.su.ac.th/objects/thesis/fulltex t/snamcn/Daranee_Klaikreuh/Bibliography.pdf

27. Pedreschi, F., C. Cocio, P. Moyano and E. Troncoso, 2008. Oil distribution in potato slices during frying. J. Food Eng., 87: 200-212. http://linkinghub.elsevier.com/retrieve/pii/S026087 7407005997

28. Pinthus, E.J., P. Weinburg and I.S. Saguy, 1995a. Deep-fat fried product oil uptake as affected by crust physical properties. J. Food Sci., 60: 770-772. http://fst.sagepub.com/cgi/content/abstract/11/3/177

29. Pinthus, E.J., P. Weinburg and I.S. Saguy, 1995b. Oil uptake in deep-fat frying as affected by porosity. J. Food Sci., 60: 767-769. http://www3.interscience.wiley.com/journal/11994 6268/abstract

30. Raoult-Wack, A.L., M. Rouziere, M. Reynes and J.M. Noel, 1996. An original application of deepfat frying dehydration of water-rich oily materials prior too oil extraction. Proceedings of the 1 st Main Meeting of Process Optimization and Minimal Processing of Foods, (MMPOMPF'96), Oliveira, JC., pp: 49-52.

31. Reddy, G.V. and H. Dias, 1993. Kinetics of deepfat frying of potato and optimization of process variables. J. Food Sci. Technol., 30: 105-108. http://www.ncfst.iit.edu/CBOT/cbotbibl.html

32. Rimac, B.S., V. Lelas, D. Rade and B. Simundic, 2004. Decreasing of oil absorption in potato strips during deep fat frying. J. Food Eng., 64: 237-241. http://cat.inist.fr/?aModele $=$ afficheN\&cpsidt $=15656826$
33. Rubnov, M. and I.S. Saguy, 1997. Fractal analysis and crust water diffusivity of a restructures potato product during deep-fat frying. J. Food Sci., 62: $135-137$.

http://www3.interscience.wiley.com/journal/11993 5276/abstract

34. Salvador, A., T. Sanz and S.M. Fiszman, 2008. Performance of methyl cellulose in coating batters for fried products. Food Hydrocolloid., 22: 1062-1067. http://www.foodqualitynews.com/Innovation/Addmethyl-cellulose-for-healthy-battered-food

35. Sanchez-Gimeno, A.C., A.I. Negueruela, M. Benito, A. Vercet and R. Oria, 2008. Some physical changes in Bajo Aragon extra virgin olive oil during the frying process. Food Chem., 110: 654-658. http://lib3.dss.go.th/fulltext/e_content/03088146/2008\%20v.110\%20n.3\%20p.547-806.pdf

36. Pinthus, E., P. Weinberg and I.S. Saguy, 2006. Gel-strength in restructured potato products affects oil uptake during deep-fat frying. J. Food Sci., 57: 1359-1360.

http://www3.interscience.wiley.com/journal/11931 9782/abstract?CRETRY $=1 \&$ SRETRY $=0$

37. Taiwo, K.A. and O.D. Baik, 2007. Effects of pretreatments on the shrinkage and textural properties of fried sweet potatoes. Lebensm. Wiss. U. Technol., 40: 661-668.

http://cat.inist.fr/?aModele $=$ afficheN\&cpsidt $=1849$ 2182

38. Ufheil, G. and F. Escher, 1996. Dynamics of oil uptake during deep-fat frying of potato slices. Lebensm. Wiss. Technol., 29: 640-644. DOI: 10.1006/fstl.1996.0097

39. Varela, G., A.E. Bender and I.D. Morton, 1988. Frying of Food: Principles, Changes, New Approaches. John Wiley and Sons Ltd., England, ISBN: 10: 0895736489, pp: 202.

40. Williams, R. and G.S. Mittal, 1999. Water and fat transfer properties of polysaccharide films on fried pastry mix. Lebensm. Wiss. U. Technol., 32: 440-445. http://cat.inist.fr/?aModele $=$ afficheN\&cpsidt $=1255$ 902

41. Lisińska, G. and W. Leszczyński, 1989. Potato Science and Technology. Elsevier Science Publishers Ltd., Essex, England, ISBN: 185166307X, pp: 391.

42. Pravisani, M.F. and A. Calvelo, 1986. A minimum cooking time for potato frying. J. Food Sci., 51: 614-617. DOI: $10.1111 / \mathrm{j} .1365-$ 2621.1986.tb13892.x 